\title{
Nutrient Intake among Children with Autism
}

\author{
Erin Moore', Tina Crook ${ }^{1 *}$, Jill James ${ }^{2}$, Dana Gonzales ${ }^{1}$ and Reza Hakkak ${ }^{1}$ \\ ${ }^{1}$ Dietetics and Nutrition, University of Arkansas for Medical Sciences, 4301 West Markham St. Slot \#627, Little Rock, AR, 72205 USA \\ ${ }^{2}$ College of Medicine, Department of Pediatrics, University of Arkansas for Medical Sciences, 1 Children's Way, Little Rock, AR, 72202 USA
}

\begin{abstract}
The objective of this study was to examine adequacy of nutrient intake and determine the impact of multivitamin use on nutrient intake in children with autism. This was a retrospective analysis of food frequency questionnaire data collected from 54 children, ages 2-8 years, in the Autism Integrated Metabolic and Genomic Endeavor Study at Arkansas Children's Hospital Research Institute, Little Rock, AR. The average percent of Kilocalories from carbohydrate, protein and fat fell within the acceptable macronutrient distribution ranges at $56 \%, 14 \%$ and $33 \%$, respectively. Mean intakes for calcium, potassium, vitamin $\mathrm{E}$, vitamin $\mathrm{D}$ and fiber were below the dietary reference intake (DRI) levels at $75 \%, 57 \%, 77 \%, 25 \%$ and $41 \%$, respectively. Mean intakes of vitamin A, thiamin, riboflavin, vitamin C, and vitamin $\mathrm{B} 6$ exceeded the DRI at $216 \%, 233 \%, 270 \%, 452 \%$ and $228 \%$, respectively. No differences were found in vitamin $\mathrm{D}$, vitamin $\mathrm{E}$, calcium, total kilocalorie, carbohydrate, protein and fat intake between children who were multivitamin users and those who were non-users. These data indicate that children with autism have diets adequate in kilocalories and macronutrients, while imbalances exist in fiber and several micronutrients. Dietary interventions for children with autism should be aimed at addressing these potential nutritional imbalances.
\end{abstract}

Keywords: Autism; Autistic disorder; Children; Dietary intake; Nutritional status; Food frequency questionnaire

Abbreviations: DRI: Dietary Reference Intake; AMDR: Acceptable Macronutrient Distribution Range; FFQ: Food Frequency Questionnaire; Autism IMAGE Study: Autism Integrated Metabolic and Genomic Endeavor Study; GI: Gastrointestinal; ASD: Autism Spectrum Disorders; AD: Autistic Disorder

\section{Introduction}

Autism spectrum disorders (ASDs) are a group of complex neuro-developmental disorders characterized by impairments in social and communication skills as well as repetitive body movements and behaviors [1]. ASDs include autistic disorder (AD), Asperger's syndrome and pervasive developmental disorder - not otherwise specified. The most recent estimates from the Centers for Disease Control reveal that one in 88 children in the United States have some type of ASD [2]. This represents a marked increase since 2000 when prevalence rates were approximately one in 150 children [2]. Boys are disproportionately affected with rates approximately five times higher than girls (1:54 boys versus 1:252 girls) [2]. The exact cause for the increased rate is unknown but may be due, in part, to increased awareness and availability of services resulting in more ASD diagnoses.

Children with ASDs often exhibit behaviors that result in feeding problems and, in turn, may impact nutrient intake. They tend to desire sameness in daily routines including eating the same foods that result in a diet that lacks variety [3]. Additionally, disturbances in routine may lead to disruptive mealtimes, and, thus poor intake.

Other possible factors that may affect nutritional status include gastrointestinal (GI) complications as well as differences in metabolism and utilization of nutrients.

GI complaints are common among children with ASDs. Diarrhea, foul smelling stools, flatulence, abdominal pain and constipation are among the most commonly reported GI problems [4]. Adams et al. [5] found that children with more severe cases of AD reported more GI symptoms.

Researchers have begun to explore metabolic abnormalities that may be present in children with ASDs [6-10]. Specifically, imbalances of some metabolic biomarkers related to oxidative stress and DNA methylation have been noted. James et al. [6,7] reported decreases in methylation and antioxidant capacity with subsequent increases in oxidative stress in children with AD. Similarly, Melnyk et al. [10] found decreased antioxidant and methylation capacity in children with $\mathrm{AD}(\mathrm{n}=68)$ when compared to groups of unaffected siblings $(\mathrm{n}=40)$ and controls $(\mathrm{N}=54)$. Increased oxidative stress in children with AD can lead to cellular damage and altered epigenetic expression. Thus, exploring these imbalances and investigating nutritional interventions that may normalize these metabolic pathways may be a critical component in treating $\mathrm{AD}$.

These potential factors affecting nutritional status make it imperative to examine the adequacy of nutrient intake in children with AD. Few studies have compared food and nutrient intake of children with $\mathrm{AD}$ to children with typical development or to standard values. Thus, the purpose of this study was to determine adequacy of nutrient intake in children with $\mathrm{AD}$ and to examine if multivitamin use affected nutrient intake levels.

\section{Materials and Methods}

Data analyzed for this study were a subset of fifty-four children who participated in the Autism Integrated Metabolic and Genomic Endeavor (IMAGE) Study, an on-going, case-control study at Arkansas Children's Hospital Research Institute, Little Rock, AR. The study was approved by the Institutional Review Board at the University of Arkansas for Medical Sciences.

Inclusion criteria for children to participate included that they be 3-10 years of age and have a diagnosis of AD. Exclusion criteria for the study included: 1) diagnosis of Asperger's syndrome or pervasive developmental disorder-not otherwise specified, 2) diagnosis of a

*Corresponding author: Dr. Tina Crook, Department of Dietetics and Nutrition 4301 W. Markham St., Mail Slot 627, Little Rock, AR 72205, USA, E-mail: tcrook@uams.edu

Received May 24, 2012; Accepted June 21, 2012; Published June 23, 2012

Citation: Moore E, Crook T, James J, Gonzales D, Hakkak R (2012) Nutrient Intake among Children with Autism. J Nutr Disorders Ther 2:115. doi:10.4172/21610509.1000115

Copyright: $\odot 2012$ Moore E, et al. This is an open-access article distributed under the terms of the Creative Commons Attribution License, which permits unrestricted use, distribution, and reproduction in any medium, provided the original author and source are credited. 
single gene or chromosomal disorder, 3) use of anti-folate medications, 4) use of high dose vitamins, nutritional or herbal supplements, and 5) use of other medications known to interfere with the study's results or scientific validity as determined by the principal investigator.

Data collected at the study visit included height and weight measurements according to standardized procedures and caregivers were queried about the child's use of supplements. Additionally, a validated food frequency questionnaire (FFQ), Block Kids 2-7 FFQ (Nutrition Quest, Berkeley, CA, USA), was administered by the study coordinator [11]. Analyses of all essential nutrients were compared to the dietary reference intake (DRI) values and acceptable macronutrient distribution ranges (AMDR) to determine dietary adequacy.

\section{Statistics}

Data were analyzed using IBM SPSS, version 19.0, statistical database software (Armonk, New York, USA). Descriptive statistics, including means and standard deviations, were used to describe study variables. One-way between groups multivariate analysis of variance (MANOVA) was performed to investigate multivitamin use with dietary intakes of vitamin $\mathrm{D}$, vitamin $\mathrm{E}$ and calcium, and to explore the impact of multivitamin use on macronutrient intake.

\section{Results}

Analyses were conducted on 54 children ( 47 males, 7 females). The uneven gender distribution reflects the increased prevalence of $A D$ in males [2]. The age and ethnic distribution of the children is summarized in Table 1. Height and weight measurements were recorded on 39 children from which body mass index (BMI) was calculated. Children's BMI categories are presented in Table 2 and are based on the Centers for Disease Control weight classifications for children ages 2-20 [12]. Twenty of the children (37\%) were taking over- the- counter multivitamin supplements and $34(63 \%)$ were not taking supplements.

\section{Macronutrient intake}

Mean daily intake of kilocalories was $1,511(S D=524.8)$. The mean intakes of carbohydrate, protein and fat grams were 211 grams $(\mathrm{SD}=$ $84.7), 51$ grams $(S D=19.2)$, and 55 grams $(S D=18.5)$, respectively. A mean of $56 \%$ kilocalories came from carbohydrate $(\mathrm{SD}=6.9), 14 \%$ from protein $(\mathrm{SD}=3.2)$ and $33 \%$ from fat $(\mathrm{SD}=5.0)$. The mean intake of dietary fiber was 10 grams (SD $=5$ ), reflecting $41 \%$ of the DRI (SD $=19$ ). No significant difference between multivitamin users and nonusers was found for the combined macronutrients (carbohydrates, protein, fat and total kilocalories), $\mathrm{F}(4,49)=2.30, \mathrm{p}=.072$; Wilks' Lambda $=.84 ;$ partial eta squared $=.16$.

\section{Micronutrient intake}

Average nutrient intake was below $100 \%$ of the DRI for calcium $(75 \%$ DRI, SD $=45)$, potassium $(57 \%$ DRI, SD $=22)$, vitamin E $(77 \%$ DRI, SD = 26), and vitamin $\mathrm{D}(25 \%, \mathrm{SD}=19)$. The average intake of vitamin $\mathrm{A}$, thiamin, riboflavin, vitamin $\mathrm{C}$, and vitamin $\mathrm{B} 6$ exceeded the DRI at $216 \%(\mathrm{SD}=110), 233 \%(\mathrm{SD}=81), 270 \%(\mathrm{SD}=109)$, $454 \%(\mathrm{SD}=282)$ and $228 \%(\mathrm{SD}=86)$, respectively. Using one-way between groups MANOVA results for the combined micronutrients (vitamin $\mathrm{D}$, vitamin $\mathrm{E}$ and calcium) showed no significant difference between children who took multivitamins and those who did not take multivitamins, $\mathrm{F}(3,50)=1.27, \mathrm{p}=.294$; Wilks' Lambda $=.93$; partial eta squared $=.07$.

\section{Discussion}

Results of this study reveal that children with AD have diets adequate

\begin{tabular}{lllllll}
\multicolumn{2}{c}{ Age (years) } & \multicolumn{2}{c}{ Males $(\mathbf{n = 4 7 )}$} & \multicolumn{3}{c}{$\begin{array}{c}\text { Females }(\mathbf{n = 7}) \\
\text { Ethnicity }\end{array}$} \\
\cline { 5 - 7 } & White $^{\mathrm{a}}$ & Black $^{\mathrm{b}}$ & Other $^{\mathrm{c}}$ & White $^{\mathrm{a}}$ & Black $^{\mathrm{b}}$ & Other $^{\mathrm{c}}$ \\
\hline 3 & 5 & 3 & 0 & 0 & 0 & 0 \\
4 & 9 & 0 & 1 & 4 & 2 & 0 \\
5 & 11 & 0 & 1 & 0 & 0 & 0 \\
6 & 5 & 1 & 1 & 1 & 0 & 0 \\
7 & 9 & 0 & 0 & 0 & 0 & 0 \\
8 & 1 & 0 & 0 & 0 & 0 & 0 \\
Total & 40 & 4 & 3 & 5 & 2 & 0 \\
\hline
\end{tabular}

Note: aWhite, Non-Hispanic; ${ }^{\mathrm{b} B l a c k}$, Non-Hispanic; ${ }^{\mathrm{C}} \mathrm{Other}-1$ child was Asian and 2 children had a mixed racial background

Table 1: Number of Children according to Ethnicity by Gender and Age ( $N=54)$.

\begin{tabular}{|c|c|c|c|c|c|c|c|c|}
\hline \multirow{3}{*}{ Age (years) } & \multirow{2}{*}{\multicolumn{4}{|c|}{ Males $(n=34)$}} & \multicolumn{4}{|c|}{ Females $(n=5)$} \\
\hline & & & & & & MI Cat & ory & \\
\hline & UW $^{\mathrm{a}}$ & $\mathrm{NW}^{\mathrm{b}}$ & $\mathrm{OW}^{\mathrm{c}}$ & $\mathrm{OB}^{\mathrm{d}}$ & UW $^{\mathrm{a}}$ & $\mathrm{NW}^{\mathrm{b}}$ & $\mathrm{OW}^{\mathrm{c}}$ & $\mathrm{OB}^{\mathrm{d}}$ \\
\hline $3(n=6)$ & 0 & 4 & 0 & 2 & 0 & 0 & 0 & 0 \\
\hline $4(n=13)$ & 1 & 5 & 0 & 2 & 1 & 4 & 0 & 0 \\
\hline $5(n=10)$ & 0 & 6 & 2 & 2 & 0 & 0 & 0 & 0 \\
\hline $6(n=6)$ & 0 & 3 & 2 & 1 & 0 & 0 & 0 & 0 \\
\hline $7(n=3)$ & 0 & 1 & 1 & 1 & 0 & 0 & 0 & 0 \\
\hline $8(n=1)$ & 0 & 0 & 0 & 1 & 0 & 0 & 0 & 0 \\
\hline Totals & 1 & 19 & 5 & 9 & 1 & 4 & 0 & 0 \\
\hline
\end{tabular}

aUW $=$ under-weight with $\mathrm{BMI}$ for age $<5 \%$; ${ }^{\mathrm{N}} \mathrm{NW}=$ normal weight with $\mathrm{BMI}$ for age 5.0-84.9\%; ' ${ }^{\circ} \mathrm{OW}=$ overweight with BMI for age $85.0-94.9 \%$; ${ }^{\mathrm{d}} \mathrm{OB}=$ obese with $\mathrm{BM}$ for age $\geq 95 \%$

Table 2: Number of Children per BMI Category by Gender and Age (N=39).

in kilocalories and macronutrients; however, some micronutrients are under- or over-consumed. Our findings are similar to reports from other researchers [3,13-15]. Edmond et al. [3] reported adequate energy intake and growth in children with ASD, although their diets were less varied when compared to a group of control children.

Although average intakes for the macronutrients were within the AMDR in the present study, some individual differences are worth noting. Eleven children (20\%) exceeded the AMDR for fat, consuming $>35 \%$ of kilocalories from fat. Similarly, Raiten and Massaro [16] reported increased fat intake among children with AD. Furthermore, Curtin et al. [17] reported the prevalence of obesity in children with autism to be $30.4 \%$ compared to $23.6 \%$ in children without autism. These findings highlight the importance of on-going nutrition assessment in children with $\mathrm{AD}$ so that early dietary interventions can be implemented to prevent obesity and related health problems.

We found intakes below the DRI for calcium, potassium, vitamin E, vitamin $\mathrm{D}$ and fiber. These data are similar to findings from other studies [13-16]. In the present study, vitamin D intake averaged only $25 \%$ of the DRI. These low levels may warrant further investigation since recent reports suggest vitamin D deficiency, especially in utero and early childhood, may be related to increased risk of autism [18]. Vitamin D has been shown to increase glutathione levels, thus increasing antioxidant capacity [19-20]. Therefore, deficiencies may alter glutathione metabolism and be a factor in the pathology of AD.

Dietary fiber intake averaged $41 \%$ of the DRI in the present study. Constipation is one of the most common complaints among children with autism [4]. Ibrahim et al. [21] found that children with AD had a higher cumulative incidence of constipation compared to children without $\mathrm{AD}$ (33.9\% versus $17.6 \%)$. Adequate dietary fiber intake may 
Citation: Moore E, Crook T, James J, Gonzales D, Hakkak R (2012) Nutrient Intake among Children with Autism. J Nutr Disorders Ther 2:115. doi:10.4172/2161-0509.1000115

\begin{tabular}{lcccc} 
& \multicolumn{2}{c}{$\begin{array}{c}\text { aMVI Users } \\
(\mathrm{n}=20)\end{array}$} & \multicolumn{2}{c}{$\begin{array}{c}\text { aMVI Non-Users } \\
(\mathrm{n}=34)\end{array}$} \\
& Mean & SD & Mean & SD \\
\hline & & & & \\
Total Kilocalories & 1689 & 614 & 1406 & 441 \\
Carbohydrates (g) & 240 & 99 & 193 & 71 \\
Protein (g) & 55 & 22 & 49 & 17 \\
Fat (g) & 61 & 21 & 51 & 16 \\
\hline
\end{tabular}

Note: ${ }^{a} \mathrm{MVI}=$ Multivitamin

Table 3: Means and Standard Deviations for Total Kilocalories and Macronutrients of Multivitamin Users and Non-Users.

alleviate this problem and should be emphasized when providing nutrition recommendations to children with $\mathrm{AD}$ and their caregivers.

It should be noted that low levels of calcium, vitamin E, vitamin D, and fiber have also been reported in children with typical development [13]. Thus, suboptimal intake of these nutrients may not be unique to children with AD. However, they are important factors to consider and address when assessing the nutritional status of this population.

We found several micronutrients including vitamin A, thiamin, riboflavin, vitamin $\mathrm{C}$, and vitamin $\mathrm{B} 6$ were consumed in levels exceeding the DRI. This may be due to the higher consumption of enriched foods and fruit juices commonly consumed by children with $\mathrm{AD}$. Other researchers have reported increased intakes of vitamin $\mathrm{C}$ [16] and vitamin B6 [13] in this population, as well.

No statistically significant differences were found in nutrient intake between children taking over-the-counter multivitamins and those not taking multivitamins. However, multivitamin users had slightly higher mean intakes of total Kilocalories, carbohydrate, protein and fat when compared to non-users (Table 3).

\section{Limitations}

This study was limited to children in Arkansas. Future studies examining dietary factors of children with $\mathrm{AD}$ in other geographic regions would add to the literature. Additionally, studies comparing nutrient intake of children with AD to children with typical development would aid in developing specific dietary recommendations for children with AD.

\section{Conclusion}

Several factors may influence the nutritional status of children with $\mathrm{AD}$ including feeding problems, GI issues and metabolic abnormalities. Our results support previous findings that children with AD underand over-consume some nutrients. Dietary interventions for children with autism should be aimed at addressing these potential nutritional imbalances.

\section{References}

1. American Psychiatric Association (2000) Diagnostic and statistical manual of mental disorders. ( $4^{\text {th }}$ edn), American Psychiatric Association, Washington, DC.

2. Centers for Disease Control and Prevention (2012) Prevalence of autism spectrum disorders: Autism and developmental disabilities monitoring network, 14 sites, United States, 2008. Morbidity and Mortality Weekly Report 61: 1-19.

3. Edmond A, Emmett P, Steer C, Golding J (2010) Feeding symptoms, dietary patterns, and growth in young children with autism spectrum disorders. Pediatrics 126: e337-e342.

4. Erickson CA, Stigler KA, Corkins MR, Posey DJ, Fitzgerald JF, et al. (2005) Gastrointestinal factors in autistic disorder: A critical review. J Autism Dev Disord 35: 713-727.

5. Adams JB, Johansen LJ, Powell LD, Quig D, Rubin RA (2011) Gastrointestinal flora and gastrointestinal status in children with autism: Comparisons to typical children and correlation with autism severity. BMC Gastroenterol 11: 22.

6. James SJ, Cutler P, Melnyk S, Jernigan S, Janak L, et al. (2004) Metabolic biomarkers of increase oxidative stress and impaired methylation capacity in children with autism. Am J Clin Nutr 80: 1611-1617.

7. James SJ, Melnyk S, Jernigan S, Cleves MA, Halsted CH, et al. (2006) Metabolic endophenotype and related genotypes are associated with oxidative stress in children with autism. Am J Med Genet B Neuropsychiatr Genet 141 947-956.

8. James SJ, Melnyk S, Fuchs G, Reid T, Jernigan S, et al. (2009) Efficacy of methylcobalamin and folinic acid treatment on glutathione redox status in children with autism. Am J Clin Nutr 89: 425-430.

9. Zecavati N, Spence SJ (2009) Neurometabolic disorders and dysfunction in autism spectrum disorders. Curr Neurol Neurosci Rep 9: 129-136.

10. Melnyk S, Fuchs GJ, Schultz E, Lopez M, Kahler SG (2012) Metabolic imbalance associated with methylation dysregulation and oxidative damage in children with autism. J Autism Dev Disord 42: 367-377

11. Cullen KW, Watson K, Zakeri I (2008) Relative reliability and validity of the block kids questionnaire among youth aged 10 to 17 years. J Am Diet Assoc 108: 862-866.

12. Barlow SE, Expert Committee (2007) Expert committee recommendations regarding the prevention, assessment, and treatment of child and adolescent overweight and obesity: Summary report. Pediatrics 120: S164-S192.

13. Herndon AC, DiGuiseppi C, Johnson SL, Leiferman J, Reynolds A (2009) Does nutritional intake differ between children with autism spectrum disorders and children with typical development? J Autism Dev Disord 39: 212-222.

14. Shearer TR, Larson K, Neuschwander J, Gedney B (1982) Minerals in the hair and nutrient intake of autistic children. J Autism Dev Disord 12: 25-34.

15. Ho HH, Eaves LC, Peabody D (1997) Nutrient intake and obesity in children with autism. Focus Autism Other Dev Disabl 12: 187-192.

16. Raiten D, Massaro T (1986) Perspectives on the nutritional ecology of autistic children. J Autism Dev Disord 16: 133-143.

17. Curtin C, Anderson SE, Must A, Bandini L (2010) The prevalence of obesity in children with autism: A secondary data analysis using nationally representative data from the National Survey of Children's Health. BMC Pediatr 10: 11

18. Bakare MO, Munir KM, Kinney DK (2011) Association of hypomelanotic skin disorders with autism: Links to possible etiologic role of vitamin-D levels in autism? Hypothesis (Tor) 9: e2.

19. Main PA, Angley MT, O'Doherty CE, Thomas P, Fenech M (2012) The potentia role of the antioxidant and detoxification properties of glutathione in autism spectrum disorders: A systematic review and meta-analysis. Nutr Metab (Lond) 9: 35.

20. Garcion E, Wion-Barbot N, Montero-Menei CN, Berger F, Wion D (2002) New clues about vitamin $D$ functions in the nervous system. Trends Endocrino Metab 13: 100-105.

21. Ibrahim SH, Voigt RG, Katusic SK, Weaver AL, Barbaresi WJ (2009) Incidence of gastrointestinal symptoms in children with autism: a population-based study. Pediatrics 124: 680-686. 